Received $\mid$ Modification $\mid$ Accepted $\mid$ Published

\title{
A COMPARATIVE STUDY TO ASSESS THE KNOWLEDGE REGARDING GERIATRIC CARE AMONG CARE TAKERS OF ELDERLY PEOPLE AT SELECTED RURAL AND URBAN FAMILIES OF VADODARA CITY
}

\author{
MR. SANJAY KUMAR DIXIT \\ M.Sc.Nursing (Community Health Nursing) Principal Pioneer Nursing College, \\ Vadodara, Gujarat
}

Corresponding email: dixitsanjay1983@gmail.com

\begin{abstract}
:
Introduction: Ageing is normal, universal and an inevitable change which taken place with the best of nutrition and health care. It involves all aspects of the organism and is largely characterized by a decline in the functional efficiency.Over the twenty-year period from 1950-1970, the proportion of people in the populationaged 65 and over was 5\%. In 1980 this age group began to increases, the government has taken a lot of incentives to achieve the goal in terms of preventive geriatric to achieving the active ageing.

Material and methods: This Comparative study was conducted to assess the knowledge of care takers regarding geriatric care among care takers of elderly people in selected rural and urban families of Vadodara city with nonexperimental descriptive research design used to achieve the goal of the study by using instrument includes, Demographical data and structured knowledge questionnaires, followed to carried out a structured interview scheduleamong 100 care takers $(\mathrm{N}=50$ rural ,N=50 urban ) those are selected by non probability purposive sampling technique. The collected data was tabulated and analyzed using descriptive and inferential statistics.

Results: The findings of the study revealed that, the majority of care takers of rural families have $56 \%$ inadequate knowledge, $28 \%$ care takers have moderate knowledge, and only 16\% caretakers have adequate knowledge whereas the majority of $46 \%$ care takers of urban families have moderate knowledge ,36\% caretaker have care takers have adequate knowledge and only very least $18 \%$ caretakers have inadequate knowledge so there is significance difference in rural and urban care takers knowledge regarding geriatric care.

Conclusion: The study conclude thatin rural families majority of caretakers have inadequate knowledge whereas in urban families'majority of caretakers havemoderate knowledge .So caretakers of urban families have much higher knowledge as compared to rural families related to geriatric care.

Key words: knowledge, geriatric care,caretakers, rural families, urban families, interview.
\end{abstract}

\section{INTRODUCTION}

Demographic ageing is a global phenomenon. In the words of Seneca; 'Old age is an incurable disease", but more recently, Sir James Sterling Ross commented: "You do not heal old age. You protect it; promote it; you extend it". Therefore old age should be regarded as a normal, inevitable, biological phenomenon.

Ageing is defined as the normal physical and behavioral changes that occur under normal environmental conditions as people mature and advance in age, Furthermore, successful ageing as anindividual's ability to adapt or adjust to the process of ageing.

The definition of "Old people" was defined as an individual is aged 65 or above, the population of the old people above 65 years old in the world will increase more than three theme until 2050.

Advent of modernity, globalization and accompanying phenomena such as industrialization, urbanization, 
migration, has put strain on the social institutions which are changing fast. Withering of joint family system and emergence of nuclear family coupled with the increasing the life expectancy and phenomenal growth in the number of elderly population have created adverse situations of the welfare and care of elderly in society.

WHO has restructured its programme on the health of the elderly and given it a new name - "Ageing and Health". The World Health Day Theme for the year 1999 has emphasized the importance of active ageing. Reflecting the rapid ageing of the population worldwide, this area of health care is becoming a dominant concern in the new millennium.

Ministry of social justice and empowerments as the model agency with regards to ageing issue. it provide basic policy guidance of elderly care in response of these social and demographic changes, the ministry of social justice and empowerment (MSJ\$E) ,Government of India formulated a national policy of elderly people(NPOP) in January 1999 to foster active and productive ageing .

\section{NEED OFTHE STUDY:-}

The ageing of population is a world -wide phenomenon, more evident in developed countries but occurring more rapidly in developing countries. ${ }^{1}$

Population ageing is the most significant result of the process known as demographic transition. Reduction of fertility leads to a decline in the proportion of the young in the population. Reduction in mortality means a longer life span for individuals. Population ageing involves a shift from high mortality/high fertility to low mortality/low fertility and consequently an increased proportion of older people in the total population. India is undergoing such a demographic transition.

The world over, there has been a rapid increase in the number of elderly people, in India, the "aged " population ( 60 years \& elder) is the second largest in the world. It is estimated that the proportion of elderly people will increase from $7.7 \%$ in 2001 to about $11 \%$ in $2020 .^{8}$
ISSN Print: 2581-8546 ISSN Online: 2582-2934

FIGURE 1: COMPARATIVE FACTS ABOUT

\section{GERIATRICS}

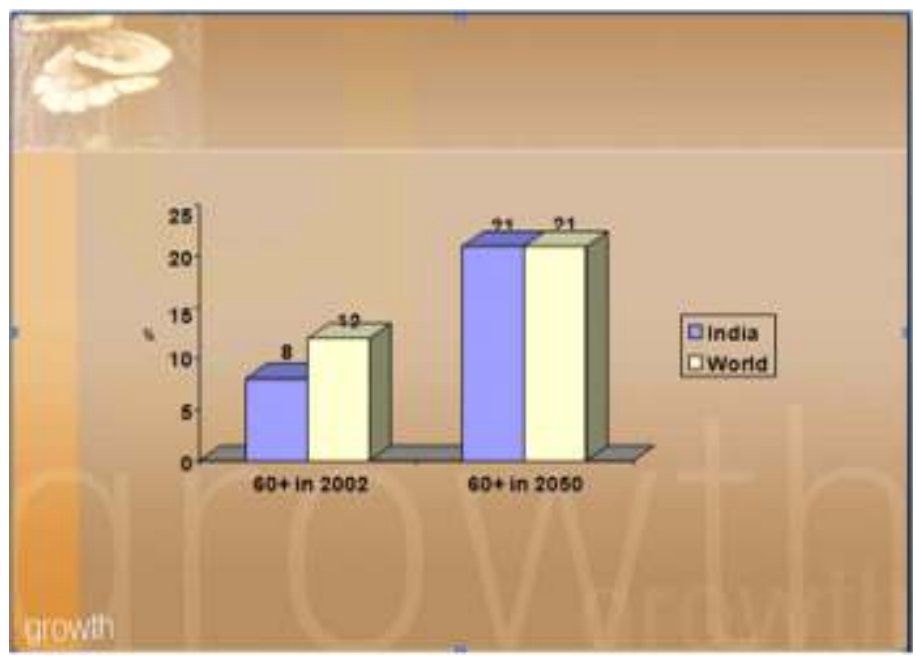

In Gujarat \% of elderly with no property by sex and place of residence, is about $30.8 \%$ in includes in rural community cover $33.1 \%$ and urban community covers the $28.4 \%$ by elderly people.

- Estimated by using the national sample survey data.

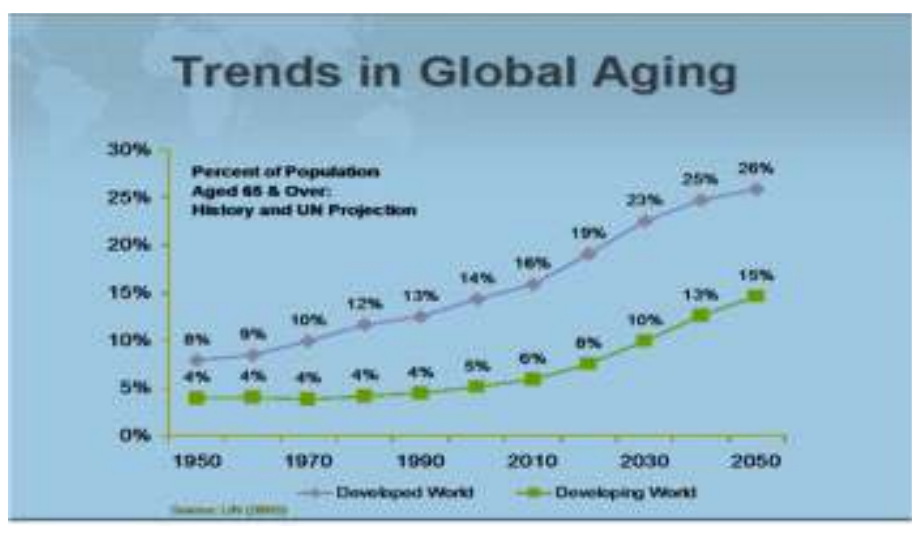

ICMR survey conducted in 1984-1985, of elderly person over 60 year of age attending geriatricclinic in rural areas and reported various ailments of elderly.1

\begin{tabular}{|l|l|}
\hline Ailment & Reported \% \\
\hline Visual impairment & 88.0 \\
\hline Locomotion Disorders & 40.0 \\
\hline Neurological complains & 18.7 \\
\hline Cardiovascular diseases & 17.4 \\
\hline Respiratory disorders & 16.1 \\
\hline Skin disorders & 13.3 \\
\hline Gastro-intestinal /abdominal & 9.0 \\
\hline Psychiatric disorders & 8.5 \\
\hline Hearing loss & 8.2 \\
\hline Genito urinary disorder & 3.5 \\
\hline
\end{tabular}




\section{TABLE 1:ICMR SURVEY REPORT}

India, like many traditional societies, today faces a unique situation in providing care for its elderly as the existing old-age support structures in the form of family, kith and kin, are fast eroding and the elderly are ill-equipped to cope alone with their lives in the face of infirmity and disability. The onus of caring for the elderly is therefore now much more on the state than the family and will necessitate the creation of adequate institutional support. While the western countries have a fairly well organised network of institutions for the care of the elderly, the growth and development of these facilities in India, which began as early as 1901, still remains inadequate. As per recent statistic, there are 1018 old age homes in India today. Out of these, 427 homes are free of cost while 153 old age homes are on pay and stay basis, 146 homes have both free as well as pay and stay facilities and detailed information is not available for 292 homes. A total of 371 old age homes all over the country are available for the sick and 118 homes are exclusive for women. A majority of the old age homes are concentrated in the developed states including Gujarat.

\section{OBJECTIVES:-}

- To assess the knowledge regarding geriatric care among care takers of elderly people at selected rural and urban families.

- To compare the knowledge regarding geriatric care among care takers of elderly people at selected rural and urban families.

- To associate the knowledge of the rural care takers of elderly people with selected demographic variables.

- To associate the knowledge of the urban care takers of elderly people with selected demographic variables.

\section{HYPOTHESIS:-}

1. There is a significant difference between the knowledge of care takers regarding geriatrics care in selected rural and urban families of Vadodara city.

2. There is a significant association between the knowledge of care takers regarding geriatric care with selected demographical variables.
ISSN Print: 2581-8546 ISSN Online: 2582-2934

\section{RESEARCH METHODOLOGY}

This Non Experimental Comparative study was conducted to assess the knowledge of care takers regarding geriatric care among care takers of elderly people in selected rural and urban families of Vadodara city with non-experimental descriptive research design used to achieve the goal of the study by using instrument includes, Demographical data and structured knowledge questionnaires, followed to carried out a structured interview scheduleamong 100 care takers $(\mathrm{N}=50$ rural, $\mathrm{N}=50$ urban $)$ those are selected by non probability purposive sampling technique. The collected data was tabulated and analyzed using descriptive and inferential statistics.

RESULTS: The findings of the study revealed that, the majority of care takers of rural families have 56\% inadequate knowledge, $28 \%$ care takers have moderate knowledge, and only $16 \%$ caretakers have adequate knowledge whereas the majority of $46 \%$ care takers of urban families have moderate knowledge ,36\% caretaker have care takers have adequate knowledge and only very least $18 \%$ caretakers have inadequate knowledge so there is significance difference in rural and urban care takers knowledge regarding geriatric care.

\section{SIGNIFICANCE OF DIFFERENCE BETWEEN OVERALL KNOWLEDGE SCORES OF CARETAKERS OF SELECTED RURAL AND URBAN FAMILES REGARDING GERIATRIC CARE}

\begin{tabular}{|c|c|c|c|c|c|c|}
\hline $\begin{array}{l}\text { Overall } \\
\text { knowledge } \\
\text { scores }\end{array}$ & $\begin{array}{l}\text { Maximum } \\
\text { Scores }\end{array}$ & Mean & \begin{tabular}{|l|} 
Standard \\
deviation
\end{tabular} & \begin{tabular}{|l|} 
Mean \\
percentage
\end{tabular} & $\begin{array}{c}\text { t- } \\
\text { Value }\end{array}$ & p-value \\
\hline Rural & 30 & 15.88 & 4.615 & 52.93 & \multirow{2}{*}{$\begin{array}{l}4.1 \\
1\end{array}$} & \multirow{2}{*}{$\begin{array}{l}.<0.0001 \\
S, p<0.05\end{array}$} \\
\hline Urban & 30 & 19.60 & 4.422 & 65.33 & & \\
\hline
\end{tabular}

Above table shows that statistically that there is significant difference in knowledge scores of caretakers regarding geriatric care in selected rural and urban families of Vadodara city. The Calculated 't'value 4.11 is much higher than the tabulated ' $t$ 'value is 1.66 at $0.05 \%$ level of significance. 
Also the calculated ' $\mathrm{p}$ ' is .>0.0001 which ideal for any distribution and compared as acceptable 0.05. So statistically prove that there is significant difference in knowledge scores of caretakers regarding geriatric care in selected rural and urban families of Vadodara city. Thus H1 is accepted.

\section{TABLE-17: COMPARISION OF KNOWLEDGE} S C O RES OF R U RAL A N D URBA N CARETAKERS BASED ON KNOWLEDGE CATEGORIES

\begin{tabular}{|c|c|c|c|}
\hline $\begin{array}{l}\text { Categories of } \\
\text { knowledge score }\end{array}$ & $\begin{array}{c}\text { Percentage } \\
\text { Range }\end{array}$ & $\begin{array}{c}\text { Rural knowledge } \\
\text { percentage }\end{array}$ & $\begin{array}{c}\text { Urban knowledge } \\
\text { percentage }\end{array}$ \\
\hline Adequate & $>\mathbf{7 5} \%$ & $16 \%$ & $36 \%$ \\
\hline Moderate & $\mathbf{5 0 - 7 5 \%}$ & $\mathbf{2 8 \%}$ & $46 \%$ \\
\hline Inadequate & $<\mathbf{5 0 \%}$ & $\mathbf{5 6 \%}$ & $18 \%$ \\
\hline
\end{tabular}

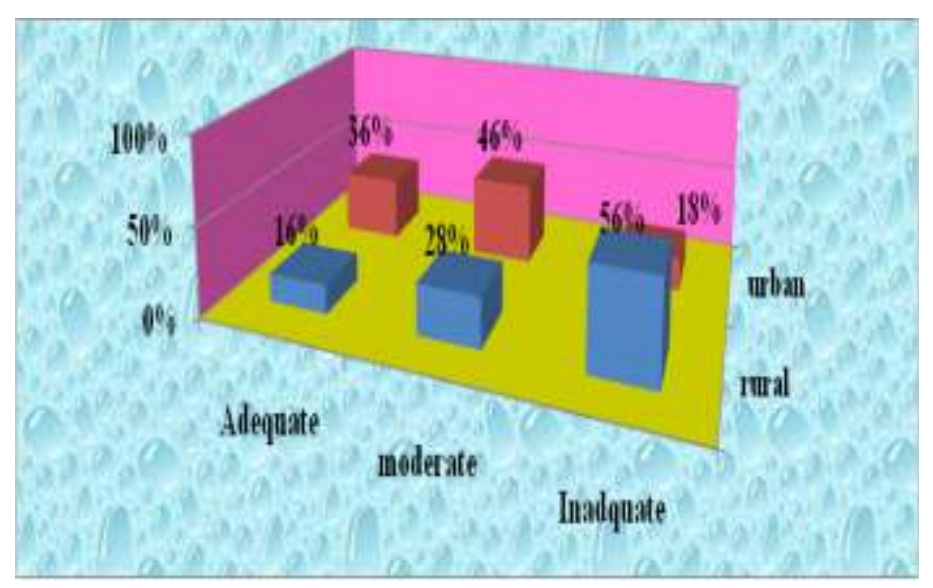

\section{COMPARISON OF KNOWLEDGE}

CATEGORIES SCORES OF CARETAKERS OF SELECTED RURAL AND URBAN FAMILIES

\section{MAJOR FINDINGS OF THE STUDY:-}

In this study It was found that $43 \%$ of caretakers belongs to the age group of $31-40$ years ,71\% of males,33\% caretakers have secondary education, $31 \%$ caretakers are labourer,38\% have their family income in between 3001-5000/month, $66 \%$ caretakers are belong to nuclear family and $50 \%$ caretakers are belongs to rural and 50\% from urban families.

The findings showed that caretakers of rural families had moderate (Mean percentage -52.93) knowledge regarding geriatric care in this overall mean score secured by rural caretakers are 15.88 on scale of 1-30.
The findings showed that caretakers of urban families had moderate (Mean percentage 65.33)knowledge regarding geriatric care. The overall mean score secured by urban caretakers are 19. on scale of 1-30.

There was significant difference between mean knowledge scores of caretakers in selected rural and urban families. The mean knowledge score of caretakers of urban families was 19.6, as compared to caretakers of rural families was 15.88 .mean percentage of the caretakers of urban families was $65.33 \%$ compared to $52.93 \%$ of caretakers of rural families. that mean there is significance difference in mean scores.Further to find out the significance difference between the knowledge scores of caretakers in rural and urban families of vadodara city by using unpaired $t$ test. For all areas of knowledge cal.' $t$ 'value $>$ tab' $t$ ' value at 0.05 level of significance. Therefore it is proved that statistically there is significant difference in knowledge scores of caretakers in selected rural and urban families of vadodara city.

Association with knowledge score of rural caretakers with selected demographic variables

The findings show that there is significant association of knowledge level of rural caretakers regarding geriatric care with Education, Occupation ,relationship with geriatric people, family income and type of family at $0.05 \%$ level of significant,

There is no significance association of knowledge level of rural caretakers regarding geriatric care with their age, gender and locality.

Association with knowledge score of urban caretakers with selected demographic variables.

The findings show that there is significant association of knowledge level of rural caretakers regarding geriatric care with Education, Occupation ,relationship with geriatric people, family income and type of family at $0.05 \%$ level of significant,

There is no significance association of knowledge level of rural caretakers regarding geriatric care with their age, gender and relationship with geriatric people. type of family, and locality.

\section{CONCLUSION}

In rural families majority of caretakers have inadequate knowledge whereas in urban families'majority of caretakers havemoderateknowledge .So caretakers of 
ISSN Print: 2581-8546 ISSN Online: 2582-2934

urban families have much higher knowledge as compared to urban families related to geriatric care.

\section{RECOMENDATIONS:}

On the basis of the findings of the study, it is recommended that:-

1. Comparative study to find out the factors that hander's the caretakers from doing geriatric care.

2. A Similar study can be replicated with intervention.(Experimental and control group)

3. A Similar study can be conducted with large samples.

4. A similar study can be conducted with planned educational programme.

5. A Similar study can be conducted professional caregivers.

6. This similar study can be conducted in institutional and non-institutional settings.

7. This study recommended for policy makers to focus the existing problems and identified Certain lacunae in the field of research on gerontology have , such as the lack of attention given towards the aged in rural India and plan must be implemented for active ageing of the nation.

\section{REFERENCES:-}

1. Park K (2009), Textbook Of Preventive And Social Medicine 20th Edition., M/S Banarsidasbhanot Publishers, 1167,Premnager,Jabalpur(M.P) Pp, 512-514.

2. "Ageing Process"Indian Journal Of Community Medicine, Vol. 33, Issue 4, Oct. 2008.

3. Sample Survey. (2002). India.

4. Barret-2004, "Essential Of Gerontological Nursing"J.B. Lippincott Company,Pp-11, www.Geriatricnursing.com

5. World Health Organization.(2000). The World Health Report 2000: Health System Improving Performance. France: Who.

6. (Robbins, 1984) Spring House Publications Mastering Geriatric Care 1st Edition, Pp 4 To 238.

7. United Nations World Assembly On Aging. Vienna 26 July - 6 August 1982.

8. K.K Gulani, Community Health Nursing ,7th edition Pp- 469,477-479.
9. (Venkoba Rao \&Madhavan, 2006)(Professor Of Psychology "Ageing In India”, Bangalore University, Bangalore, India .World Health OrganizationGeneva2006.

10. National Sample Survey Organization. SocioEconomic Profile And Security Scheme Of Aged Persons. Sarvekshana, (1999) Xv, Nos. 1-2, Issue No. 49.

11. Indian Journal Of Community Medicine, Vol. 33, Issue 4, Oct. 2008.

12. Bradley, J. And Fisher, M. "Successful Aging, Life Satisfaction And Generativity In Later Life". International Journal Of Aging And Human Development, Yale Uinivercity ,41(3), 239- 250, 1995.

13. United Nations. "The State Of The World's Population Ageing:. 1995 Report. 1995.

14. European Commission [Ec], 2006; Who,Indian Journal Of Gerontology,, Vol. 21', Issue 13, Oct. 2006.

15. "Cadenza: A Jockey Club Initiative For Seniors", Chinese University Of Hong Kong And The Faculty Of Social Sciences.

16. Directory Of Old Age Homes In India, Help Age India, 2002).

17. Polit And Hungler (1999),'Nursing Research Principles \& Methods', Philadelphia J.B. Lippincott.

18. BasvanthappaBt, Nursing Research, Jaypee Publication, 2nd Edition., Pp: 105,92,188, $195,224,437$

19. Sorensen And Lunckmann's "Basic Nursing,A Psychological Approach"3rdEdition .P.Pt 32-33.

20. Nursing Theories, BtBasavanthappa, JaypeeBrothers,New Delhi,P.Pt-384-386.

\section{Others :}

21. Health Action, June,2007,P.G.No.4-15

22. Http.//Www.Google. Com.

23. File://Localhost/H:/Benefits.Htm

24. Journal Health of Geriatric, June,2006,P. 9

25. www.Emedicine.Com

26. www.Scrubd.Com,Www.Geriatricnursing.Com 